\title{
Papers
}

\section{Sexual behaviour of adolescents in Nigeria: cross sectional survey of secondary school students}

\author{
Gail B Slap, Lucy Lot, Bin Huang, Comfort A Daniyam, Therese M Zink, Paul A Succop
}

\begin{abstract}
Objectives To determine whether family structure (polygamous or monogamous) is associated with sexual activity among school students in Nigeria. Design Cross sectional school survey with a two stage, clustered sampling design.

Participants 4218 students aged 12-21 years attending 39 schools in Plateau state, Nigeria. Responses from 2705 students were included in the analysis.

Main outcome measure Report of ever having had sexual intercourse. Variables of interest included sexual history, age, sex, religion, family polygamy, educational level of parents, having a dead parent, and sense of connectedness to parents and school. Results Overall 909 students (34\%) reported ever having had sexual intercourse, and 1119 (41\%) reported a polygamous family structure. Sexual activity was more common among students from polygamous families ( $42 \%$ of students) than monogamous families $(28 \%)\left(\chi^{2}=64.23 ; \mathrm{P}<0.0001\right)$. Variables independently associated with sexual activity were male sex (adjusted odds ratio 2.52 (95\% confidence interval 2.05 to 3.12)), older age (1.62 (1.24 to 2.14)), lower sense of connectedness with parents (1.87 (1.48 to 2.38)), having a dead parent (1.59 (1.27 to 2.00$)$ ), family polygamy (1.58 (1.29 to 1.92)), lower sense of connectedness with school (1.25 (1.09 to 1.44)), and lower educational level of parents (1.14 (1.05 to 1.24)). Multistep logistic regression analysis showed that the effect of polygamy on sexual activity was reduced by $27 \%$ by whether students were married and $22 \%$ by a history of forced sex.

Conclusions Secondary school students in Nigeria from a polygamous family structure are more likely to have engaged in sexual activity than students from a monogamous family structure. This effect is partly explained by a higher likelihood of marriage during adolescence and forced sex. Students' sense of connectedness to their parents and school, regardless of family structure, decreases the likelihood of sexual activity, and fostering this sense may help reduce risky sexual behaviour among Nigerian youth.
\end{abstract}

\section{Introduction}

One in five Africans and one in three African adolescents live in Nigeria, the most populous country in Africa. Nigeria's birth rate for adolescents is one of the highest in the world, and the prevalence among female adolescents in Nigeria of sexually transmitted infections, including HIV, is climbing rapidly. ${ }^{1}$ In an effort to reduce its high maternal and infant mortality and high rates of sexually transmitted infection and dropout from school, Nigeria developed a national reproductive health policy in 2000 that focuses on preventing risky sexual behaviours during adolescence. ${ }^{2}$

The programme has been hampered, however, by outdated and incomplete information on the sexual knowledge, attitudes, and behaviours of adolescents in Nigeria. The importance of clarifying needs before intervening is highlighted by the recent evaluation of a sex education intervention in Nigeria and Ghana. ${ }^{3}$ The evaluation showed that the programme was effective for young people in school but not for young people out of school, because of differences in sexual experience and knowledge. Had the differences been recognised earlier, modification of the intervention or narrowing the target population might have improved the effectiveness and lowered the cost of the overall programme.

While such studies suggest that sexual knowledge is higher among young people out of school, sexual experience while still in school may prompt students to acquire sexual knowledge and to move out of school. In Nigeria pregnancy and motherhood mark the end of school attendance, and by age 16 years $21 \%$ of female adolescents are either pregnant or have given birth. ${ }^{1}$ The most recent national data from Nigeria indicate that $30 \%$ of female and $36 \%$ of male adolescents are enrolled in secondary school. Therefore closing the gap between the sexes is only the first of many steps to increase access to school among all young people in Nigeria. ${ }^{4}$

The impact of family and school on adolescent health has been shown repeatedly by studies in North America and western Europe. ${ }^{5-8}$ The countries producing this research, however, differ dramatically from Nigeria and most countries of Africa in family structure, school attendance, and educational attainment. Polygamy, defined as the marriage of one husband to two or more wives simultaneously, is one of the most striking differences, with $30-50 \%$ of adults in Nigeria reporting current or past polygamy. ${ }^{9}$ Compared with families in which the parents are monogamous, in families in Africa with a polygamous structure

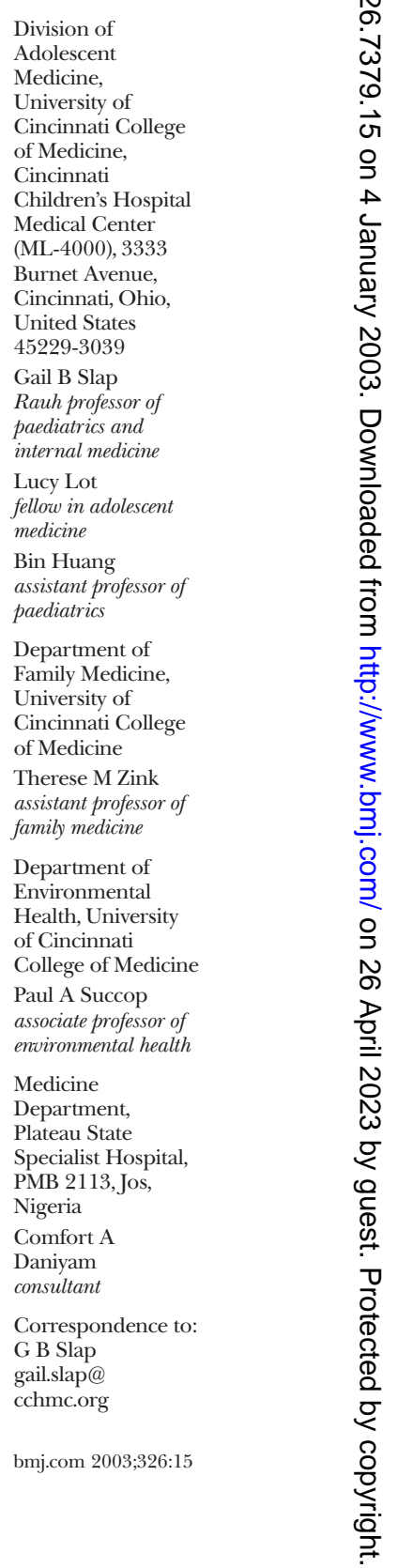


the age at which female children first get married is lower, the age difference between spouses is greater, husbands and wives have completed fewer years of school, children have more problems related to school, and adolescents have more substance misuse. ${ }^{10-14}$ No studies published in Nigeria or elsewhere, however, have explored the effects of polygamy on adolescent sexual behaviour or reproductive health.

This study's primary objective was to determine whether family structure (monogamous or polygamous) is associated with initiation of sexual intercourse among adolescents in Nigeria and, if so, to identify characteristics of the family that mediate the association. We hypothesised that adolescents from a family with a polygamous structure are more likely than adolescents from a monogamous situation to have had sexual intercourse and that the association between polygamy and adolescent sexual behaviour is mediated by the adolescents' sense of connectedness to their parents.

\section{Methods}

\section{Background}

Nigeria has 126 million people in more than 250 ethnic groups. The major languages are English (official language), Hausa, Yoruba, Igbo, and Fulani. Most of Nigeria's 36 states adhere to English common law, though Islamic law is practised in some northern states. Since the 1999 restoration of a civilian government-after nearly 30 years of military dictatorship in the four decades since independence--Nigeria has struggled with social and political unrest. The prevalence of HIV/AIDS has increased steadily through the $1990 \mathrm{~s}$, maternal and infant mortality are high, and the average life expectancy is 51 years. ${ }^{2}$

\section{Survey site}

The study took place in Plateau state, in central Nigeria. Except for its capital city, Jos, the state is rural and agrarian. Its population includes 20 ethnic groups distributed across 17 local government areas and 11 school districts. English is the primary language of instruction in schools, and by the secondary level all students can read and write in basic English. Since the change of government in 1999 school schedules and student attendance have been erratic. Although conditions had improved by the time of our survey, many schools were unable to produce reliable records of student enrolment.

\section{Participants}

The study protocol was approved by Plateau state's Ministry of Education and by the institutional review board of Cincinnati Children's Hospital Medical Center. We used a clustered sampling design to select government funded secondary schools in the first stage and students in the second stage. Day schools were grouped by district, with boarding schools as a 12th group, and then the proportion of students in each group determined the number of schools that were randomly selected from that group. Although the research plan called for the random selection of 25\% of day students and $12 \%$ of boarding students equally distributed by sex and age group (12-14, 15-17, and 18-21 years), many schools used convenience sampling to avoid further disruption in routine. In all, 90307 secondary students were enrolled in 185 schools in Plateau state; the study sample consisted of 4218 students in 39 schools.

\section{Questionnaire}

A self administered, English language questionnaire comprising 96 multiple choice items was developed for the study. Most of the items were adapted from existing surveys. ${ }^{15-17}$ Nigerian adolescents and health professionals reviewed preliminary drafts of the questionnaire for comprehensibility and acceptability. The items comprised seven items on participants' sociodemographic characteristics, 12 on their school, nine on the woman identified by the participant as "mother," nine on the man identified as "father," 15 on family relationships, 18 on health and health care, 16 on sexual and reproductive history, and 10 on sexually transmitted infections, including HIV.

\section{Data collection}

Data collection took place from 10 March to 24 March 2000. Two teams of trained research assistants administered the survey during a 60-90 minute class. Students were told they could leave any questions blank and that their answers would remain anonymous and confidential. The research assistants distributed the questionnaires to the students, remained in the classroom during administration, and transported the completed questionnaires from the schools.

\section{Data analysis}

Teleform version 6.1 (Cardiff Software, San Diego, CA) was used to scan and transform the answer sheets into computer text, which was converted to an SAS database (SAS Institute, Cary, NC). Answer sheets were excluded from the analyses if students failed to answer yes or no to the question "Have you ever had sexual intercourse (sex with another person)?" (n=202), if they gave inconsistent answers to this question and two other questions about sexual history $(n=809)$, or if they gave five or more invalid answers to the remaining 93 questions ( $\mathrm{n}=502)$. Excluded and included students were compared for differences in sex, age, year level at school, place of residence, and religion. Because some students were not selected randomly and some records of enrolment were unreliable, as discussed above, we analysed the unweighted data with adjustment for design effects.

The primary outcome measure was sexual intercourse ever (sexual activity), defined as a "yes" response to the question "Have you ever had sexual intercourse (sex with another person)?" Family polygamy was defined as a "yes" response to either or both of the questions "Has your father ever had more than one wife at the same time?" and "Have you ever lived in a household where two or more women were married to one man at the same time?"

Multi-item variables (box) were adapted from measures constructed for the US national longitudinal study on adolescent health. ${ }^{17}$ These variables were coded so that higher scores represented more desirable conditions. Responses of students who answered $<75 \%$ of the items in a set were excluded from analyses of the given variable. Missing responses for students who answered $\geqslant 75 \%$ were assigned the student's mean score for the set. 
We used $\chi^{2}$, Wilcoxon's rank sum, and $t$ tests to identify associations between sexual intercourse ever (sexual activity), family polygamy, and each of the independent variables. To correct for multiple comparisons we set the significance level conservatively at $\mathrm{P}<0.01$. We used logistic regression to estimate the probability of sexual activity as a function of family polygamy, adjusted for the four design effects: school group, school type (coeducational, same sex, day, boarding), and age and sex of the participant. Each variable associated with both sexual activity and family polygamy was added to the logistic regression model, and the reduction in the $\beta$ coefficient for family polygamy was calculated as an estimate of the variable's mediating effect on the association between sexual activity and family polygamy. ${ }^{18}$ We used stepwise logistic regression to test the hypothesis that family polygamy is independently associated with sexual activity. The four design variables and all variables associated with sexual activity at $\mathrm{P}<0.05$ were entered in the regression analysis, and those that remained significant at $\mathrm{P}<0.01$ were retained.

\section{Results}

Table 1 compares the 2705 participants whose responses were included in the analysis with the 1513 students whose answer sheets did not meet inclusion criteria. The included students were older, in higher school grades, and more likely to live in cities and to identify themselves as Christian than excluded students. They did not differ from excluded students, however, by sex or by type of school.

Table 2 compares the characteristics of the 909 $(33.6 \%)$ participants who reported having had sexual activity and the 1796 (66.4\%) who denied sexual activity. Sexual activity was less common among female than male students (23.2\% versus $42.7 \%$ ), less common among female students attending female only boarding schools than other schools $(7.7 \%$ versus $24.3 \%$ $\left(\chi^{2}=11.38 ; \quad \mathrm{P}=0.0008 ;\right.$ data not shown $\left.)\right)$, and less common among students living in urban rather than rural locations.

The mean age of sexual initiation was 14.8 (SD 2.8) years overall: 14.6 (2.8) for male students and 15.2 (2.6) years for female students $(\mathrm{P}=0.002)$. Older age but not level of class in school was associated with sexual activity, supporting the field team's impression that graded classes included students with a range of ages. In the youngest age group, $25.3 \%$ of 12 year olds and 30.9\% of 14 year olds reported sexual activity $\left(\chi^{2}=1.49\right.$; $\mathrm{P}=0.22)$, suggesting that sexual initiation is more likely at age $\leqslant 12$ years than it is between 12 and 14 years.

Most students $(87.7 \%)$ identified themselves as Christian, $11.8 \%$ as Muslim, and $0.4 \%$ as having another religion. The proportion of students reporting sexual activity did not differ between Christian (33.1\%) and Muslim (36.5\%) students. Nearly all $(96.6 \%)$ the students said that religion was very important to them, and the proportion of students reporting sexual activity increased as religious importance decreased $(\mathrm{P}<0.0001)$.

Family polygamy, whether a parent was dead, and lower educational level of parents were associated with sexual activity (table 3 ). Family polygamy was reported by 1119 students overall $(41.4 \%)$. The proportions of

\section{Multi-item variables}

Parent-teen connectedness

Participants rated five statements separately for each parent on a five point Likert scale:

She $(\mathrm{He})$ cares about me

She $(\mathrm{He})$ is warm and loving toward me

I feel close to my mother (father)

I am happy with my relationship with my mother (father)

My mother (father) and I are close to each other

The higher score for each statement was used to calculate a mean for the five items. Potential scores for the variable thus ranged from 1 (low connectedness) to 5 (high connectedness). Cronbach's $\alpha$ was 0.79 for the scores for mothers and 0.84 for fathers.

\section{Parent-teen activities}

Participants gave the number of activities, out of a list of 10 , that they did with each parent. The final score, which could range from 0 to 10 , was the higher of the two numbers.

\section{Parental presence}

Participants gave a score ranging from 0 (never) to 3 (always) on parental presence at different times of day:

Think about a typical week when you are at home. How often is at least one of your parents at home with you during the following times of day? When you wake up in the morning

At breakfast time

At supper (evening meal) time

When you go to bed

Each participant's scores were summed to yield the final score, which thus had a potential range of 0 (low parental presence) to 12 (high parental presence).

\section{Parental expectations}

Participants rated five statements separately for each parent on a five point Likert scale from not at all disappointed to extremely disappointed:

How disappointed would your mother (father) be if each of the following happened:

You did not finish secondary school

You did not graduate from university

You did not get married

You did not have a child after you were married

You became pregnant or got someone pregnant before marriage

The higher response to each item was used to calculate a mean for the five items. The final score could thus range from 1 (low expectations) to 5 (high expectations). Cronbach's $\alpha$ was 0.80 for the maternal scale and 0.83 for the paternal scale.

\section{School connectedness}

Consisted of six items rated on a five point Likert scale:

I feel close to people at school

I feel like I am part of this school

I am happy to be at this school

I feel safe in my school

My teachers are interested in me as a person

The teachers at my school treat me fairly

The final score was the mean score for the six items, thus the potential range was 1 (low connectedness) to 5 (high connectedness). Cronbach's $\alpha$ for this six item scale was 0.71 , compared with 0.59 for the original eight item scale from the US longitudinal study on adolescent health. ${ }^{17}$

students reporting sexual activity were $42.3 \%$ in students from polygamous families and $27.5 \%$ in students from monogamous families. Sexually active students had lower mean scores for parent-teen connectedness, parent-teen activities, parental presence, and school connectedness.

Of students who reported having had sexual intercourse, $57.1 \%$ of male students and $48.3 \%$ of female students said they had had more than one sexual partner, $53.5 \%$ and $61.2 \%$ had used condoms or other birth control, $30.5 \%$ and $38.4 \%$ had been treated for a sexually transmitted disease, and $22.7 \%$ and $24.5 \%$ had 
Table 1 Comparison of students whose answer sheets were included in the analyses with students whose answer sheets were excluded. Values are numbers (\%) of students unless stated otherwise

\begin{tabular}{|c|c|c|c|c|}
\hline Characteristic* & $\begin{array}{l}\text { Included } \\
(\mathrm{n}=2705)\end{array}$ & $\begin{array}{l}\text { Excluded } \\
(n=1513)\end{array}$ & $\chi^{2}$ & $P$ value \\
\hline Age (years) (SD) & $16.3(2.3)$ & $16.0(2.4)$ & - & $<0.0001 \dagger$ \\
\hline Current year level (SD) in secondary school & $3.0(1.7)$ & $3.4(1.6)$ & - & $<0.0001 \ddagger$ \\
\hline Place of residence: & & & 99.39 & $<0.0001$ \\
\hline City & $1785(68.0)$ & $768(52.7)$ & & \\
\hline Village & $733(27.9)$ & $599(41.1)$ & & \\
\hline Nomad & $106(4.0)$ & $91(6.2)$ & & \\
\hline Religion: & & & 55.68 & $<0.0001$ \\
\hline Christianity & $2372(87.8)$ & $1192(80.4)$ & & \\
\hline Islam & $319(11.8)$ & $262(17.7)$ & & \\
\hline Other & $10(0.4)$ & $29(2.0)$ & & \\
\hline Importance of religion: & & & 130.01 & $<0.0001$ \\
\hline Very important & $2601(96.6)$ & $1311(87.5)$ & & \\
\hline Important & $67(2.5)$ & $125(8.3)$ & & \\
\hline Not important & $24(0.9)$ & $62(4.1)$ & & \\
\hline
\end{tabular}

*Only characteristics with differences that are significant at the level of $\mathrm{P}<0.05$ are shown. tWilcoxon's rank sum test.

$\ddagger$ Student's $t$ test, applied to ordinal data for descriptive purposes.

Table 2 Number (\%) of students who reported or denied ever having had sexual intercourse

\begin{tabular}{|c|c|c|c|c|}
\hline \multirow[b]{2}{*}{ Characteristic } & \multicolumn{2}{|c|}{ Sexual intercourse ever } & \multirow[b]{2}{*}{$\chi^{2}$} & \multirow[b]{2}{*}{$P$ value } \\
\hline & No & Yes & & \\
\hline Total & $1796(66.4)$ & 909 (33.6) & & \\
\hline What is your sex? & & & 113.17 & $<0.0001$ \\
\hline Male & $832(57.3)$ & $619(42.7)$ & & \\
\hline Female & $955(76.8)$ & $289(23.2)$ & & \\
\hline $\begin{array}{l}\text { How many years old were you on your last } \\
\text { birthday? }\end{array}$ & & & 35.44 & $<0.0001$ \\
\hline $12-14$ & $463(72.2)$ & $178(27.9)$ & & \\
\hline $15-17$ & 755 (69.2) & $335(30.8)$ & & \\
\hline $18-21$ & $575(59.3)$ & $394(40.7)$ & & \\
\hline What class are you in? & & & 5.48 & 0.36 \\
\hline Junior 1 & $128(66.3)$ & $65(33.7)$ & & \\
\hline Junior 2 & $289(63.0)$ & $170(37.0)$ & & \\
\hline Junior 3 & 341 (68.5) & $157(31.5)$ & & \\
\hline Senior 1 & 408 (68.2) & $190(31.8)$ & & \\
\hline Senior 2 & $337(67.0)$ & $166(33.0)$ & & \\
\hline Senior 3 & $281(64.0)$ & $158(36.0)$ & & \\
\hline Type of school: & & & 29.64 & $<0.0001$ \\
\hline Coeducational day & $1306(66.7)$ & $652(33.3)$ & & \\
\hline Coeducational boarding & $265(62.5)$ & $159(37.5)$ & & \\
\hline Male boarding & $144(61.3)$ & $91(38.7)$ & & \\
\hline Female boarding & $73(92.4)$ & $6(7.6)$ & & \\
\hline $\begin{array}{l}\text { How would you describe the place where you } \\
\text { live? }\end{array}$ & & & 17.31 & 0.0002 \\
\hline City or town & $1221(68.7)$ & $556(31.3)$ & & \\
\hline Village & $446(61.0)$ & $285(39.0)$ & & \\
\hline Nomad & $61(57.6)$ & $45(42.5)$ & & \\
\hline What is your religion? & & & 11.38 & $0.0098^{*}$ \\
\hline Christianity & $1582(67.0)$ & $781(33.1)$ & & \\
\hline Islam & $202(63.5)$ & $116(36.5)$ & & \\
\hline Other & $2(20.0)$ & $8(80.0)$ & & \\
\hline None & $1(50.0)$ & $1(50.0)$ & & \\
\hline How important is religion to you? & & & 44.37 & $<0.0001$ \\
\hline Very important & $1757(67.6)$ & $844(32.5)$ & & \\
\hline Important & $27(40.3)$ & $40(59.7)$ & & \\
\hline Not important & $5(20.8)$ & $19(79.2)$ & & \\
\hline
\end{tabular}

${ }^{*}$ No significant difference between Christianity and Islam in the rates of sexual activity.

been treated for HIV/AIDS (table 4). Forced sexual intercourse was reported by $32.0 \%$ of male students and $45.0 \%$ of female students, and sex in exchange for food, money, drugs, or shelter by $26.1 \%$ and $32.6 \%$. Of 183 male students who reported having been forced to have sexual intercourse, $79(43.2 \%)$ reported a history of sex with a person of the same sex, compared with 103 of $383(26.9 \%)$ who reported no forced sexual intercourse.

Logistic regression modelling of sexual activity as a function of family polygamy gave an odds ratio of 1.58 (95\% confidence interval 1.29 to 1.92 ), after adjustment for the four design effects. The effect of family polygamy on sexual intercourse remained significant at $\mathrm{P}<0.01$ when each covariate was added to the baseline model. Having been married and whether the participants were forced to have sexual intercourse decreased the $\beta$ coefficient for family polygamy by $26.7 \%$ and $22.1 \%$, respectively. Each of the other nine variables reduced the effect by $12.9 \%$ or less.

The strong association between sexual activity, marriage, and forced sex resulted in unstable estimation of maximum likelihood in the stepwise logistic regression analysis. When marriage and forced sex were excluded from the analysis, the best subset of variables predicting sexual activity were male sex, lower parent-teen connectedness, older age, having a dead parent, family polygamy, lower school connectedness, and lower parental education (table 5).

\section{Discussion}

The findings confirm the primary hypothesis that sexual activity is more common among adolescents from polygamous families. The findings do not support the secondary hypothesis that parent-teen connectedness mediates the relation between family polygamy and adolescent sexual activity. Marriage and forced sexual intercourse are common among Nigerian school students and may help explain the association between family polygamy and sexual initiation before or during adolescence.

\section{Strengths and weaknesses of the study}

The strengths of this study are its articulation of hypotheses, a sample of adequate size for testing the hypotheses, inclusion of students of both sexes, use of items from validated survey instruments, and adaptation of materials and methods to the Nigerian context. Despite the social and political turmoil throughout Nigeria during the period of data collection, participation by schools and students was uniformly high.

However, the study has weaknesses that may affect its results or interpretation. Non-random selection of participants in some schools may have resulted in a sample that did not represent the population of secondary school students in Plateau state. Furthermore, although Plateau state is broadly representative of Nigeria, it is just one of 36 states in the country. The sociodemographic profiles of excluded and included students differed, and their sexual behaviours and family structures may also have differed. Under-reporting of sexual activity by school students in Nigeria is likely, given the harsh societal reaction to behaviours that are deemed sexual offences in much of the country. Female students who are pregnant or who have had babies typically leave school. Given Nigeria's low use of contraception and high birth rates, such dropout from school is likely to skew the female student population towards students who are sexually inactive. Finally, the study collected data only from adolescents in school. In 
a country where less than a third of adolescents attend school, the results cannot be generalised to all adolescents nationwide.

\section{Comparisons with other countries}

Many of our findings are supported by earlier studies performed in African and Western countries. The finding that family polygamy was not associated with a particular religion is consistent with the theory that polygamy reflects a country's child mortality and its proportion of children in work more than its religious profile. ${ }^{19}$ Studies in Nigeria, South Africa, and Israel have shown that children from polygamous families have higher rates of behavioural and school problems. ${ }^{10-12} 19{ }^{20}$ Studies in North and South America have shown strong associations between adolescent sexual behaviour and interpersonal family relationships, the education, presence, and expectations of parents, and the connectedness of the adolescents to parents and school..$^{17-26}$

There is evidence in developed and in developing countries that acknowledging the sexual activity of adolescents and meeting their sexual health needs with targeted education and preventive care services can help reduce risky sexual behaviour and its consequences. ${ }^{27}{ }^{28}$ The sexual health needs of young people in Nigeria are high, as evidenced by the prevalence of pregnancy and sexually transmitted disease, including HIV/AIDS. By age 13 years over a quarter of the students in our study were sexually active. Among US students surveyed in the same year (1999), sexual activity by age 13 years was reported by $5.5 \%$ of white students, $20.5 \%$ of black students, and $9.2 \%$ of Hispanic students. Whereas 39\% of female students in our study had had a past or current pregnancy, the rate among female high school students in the United States in the same year was $7.6 \%{ }^{16}$

\section{Conclusions}

The findings of our study can help programme planners in Nigeria tailor prevention strategies to the needs of adolescent school students but should not be generalised to adolescents who are out of school. Work that advances our understanding of the contexts of time, place, and people around adolescents in Nigeria is needed if we are to interpret international research correctly and plan interventions that are appropriate and effective.

Contributors: GBS generated the study hypotheses; supervised development of the survey, data analysis, and interpretation; and prepared all drafts of the manuscript. LL developed the sampling strategy; prepared, coded, and pretested the survey instrument; supervised data collection; and helped with entry of data. BH contributed to the design of the study, did all statistical analyses, and provided written summaries of the quantitative findings. CAD provided liaison between the schools, field teams, and investigators; helped with pretesting and data collection supported students and schools after data collection; and helped export the raw data to the United States for analysis. TMZ contributed to the study design, development of the survey, and critical review of the manuscript. PAS supervised development of the study design and consulted on the statistics. GBS acts as guarantor for the paper.

Competing interests: None declared.

1 Joint United Nations Programme on HIV/AIDS. Nigeria: epidemiological fact sheet on HIV/AIDS and sexually transmitted infections. Geneva: UNAIDS and WHO, 2000. (2000 update.)

2 World Health Organization. Nigeria: country progress report. Geneva: WHO, 2001.
Table 3 Characteristics of family and school of students who reported or denied having ever had sexual intercourse, and scores on inter-item variables. Figures are number $(\%)$ of students unless stated otherwise

\begin{tabular}{|c|c|c|c|c|}
\hline \multirow[b]{2}{*}{ Characteristic } & \multicolumn{2}{|c|}{ Sexual intercourse ever } & \multirow[b]{2}{*}{$\chi^{2}$} & \multirow[b]{2}{*}{$P$ value } \\
\hline & No & Yes & & \\
\hline Total & $1796(66.4)$ & $909(33.6)$ & & \\
\hline Family polygamy: & & & 64.23 & $<0.0001$ \\
\hline Yes & $646(57.7)$ & $473(42.3)$ & & \\
\hline No & $1150(72.5)$ & $436(27.5)$ & & \\
\hline Is the woman you refer to as your mother alive? & & & 40.64 & $<0.0001$ \\
\hline Yes & $1647(68.8)$ & $746(31.2)$ & & \\
\hline No & $93(53.3)$ & $106(46.7)$ & & \\
\hline Is the man you refer to as your father alive? & & & 31.17 & $<0.0001$ \\
\hline Yes & $1533(69.2)$ & $684(30.9)$ & & \\
\hline No & $188(54.0)$ & $160(46.0)$ & & \\
\hline Highest school level completed by a parent: & & & 52.45 & $<0.0001$ \\
\hline Primary school & $569(59.2)$ & $393(40.9)$ & & \\
\hline Secondary school & $413(62.7)$ & $246(37.3)$ & & \\
\hline Some university & $55(69.6)$ & $24(30.4)$ & & \\
\hline Graduated university & $571(75.3)$ & $187(24.7)$ & & \\
\hline \multicolumn{5}{|l|}{ Mean (SD) score on inter-item variables } \\
\hline Parent-teen connectedness & $4.8(0.4)$ & $4.6(0.5)$ & - & $<0.001$ \\
\hline Parent-teen activities & $5.1(2.7)$ & $4.3(2.9)$ & - & $<0.001$ \\
\hline Parental presence & $7.9(3.1)$ & $7.2(3.0)$ & - & $<0.001$ \\
\hline Parental expectations & $4.2(1.1)$ & $4.1(1.0)$ & - & 0.03 \\
\hline School connectedness & $4.1(0.7)$ & $3.9(0.8)$ & - & $<0.001$ \\
\hline
\end{tabular}

Table 4 Sexual histories of students who report ever having had sexual intercourse

\begin{tabular}{lcc} 
& $\begin{array}{c}\text { No }(\%) \text { of male } \\
\text { students }(\mathbf{n}=\mathbf{6 1 9})\end{array}$ & $\begin{array}{c}\text { No (\%) of female } \\
\text { students }(\mathbf{n}=\mathbf{2 8 9})\end{array}$ \\
\hline Current or past marriage & $121(19.7)$ & $80(28.6)$ \\
\hline More than one partner in your lifetime & $350(57.1)$ & $139(48.3)$ \\
\hline Forced to have sexual intercourse & $191(32.0)$ & $126(45.0)$ \\
\hline Sex in exchange for food, money, drugs, or shelter & $158(26.1)$ & $92(32.6)$ \\
\hline Use of condoms or other birth control & $318(53.5)$ & $161(61.2)$ \\
\hline Ever been pregnant or made someone pregnant & $204(33.1)$ & $110(38.9)$ \\
\hline Treatment for a sexually transmitted disease & $189(30.5)$ & $111(38.4)$ \\
\hline Treatment for HIV/AIDS ever & $135(22.7)$ & $67(24.5)$ \\
\hline
\end{tabular}

Table 5 Variables that best predict students ever having had sexual intercourse (results of stepwise logistic regression model)

\begin{tabular}{lc} 
Variable & Adjusted odds ratio $\mathbf{( 9 5 \%} \mathbf{~ C l )}$ \\
\hline Male sex & $2.52(2.05$ to 3.12$)$ \\
\hline Lower parent-teen connectedness & $1.87(1.48$ to 2.38$)$ \\
\hline Age $18-21$ years & $1.62(1.24$ to 2.14$)$ \\
\hline Having a dead parent & $1.59(1.27$ to 2.00$)$ \\
\hline Family polygamy & $1.58(1.29$ to 1.92$)$ \\
\hline Lower school connectedness & $1.25(1.09$ to 1.44$)$ \\
\hline Lower education level of parents & $1.14(1.05$ to 1.24$)$ \\
\hline
\end{tabular}

3 Brieger WR, Delano GE, Lane CG, Oladepo O, Oyediran KA. West African Youth Initiative: outcome of a reproductive health education program. J Adolesc Health 2001;29:436-46.

4 Population Reference Bureau. Improving reproductive health in developing countries. Washington, DC: Population Reference Bureau, 1997.

5 Blum RW. Healthy youth development as a model for youth health promotion: a review. J Adolesc Health 1998;22:368-75.

6 Dryfoos JG. Adolescents at risk:prevalence and prevention. New York: Oxford University Press, 1990.

7 Resnick MD, Harris LJ, Blum RW. The impact of caring and connectedness on adolescent health and well-being. J Paediatr Child Health 1993;29(suppl):s1-9.

8 Scales P. The role of family support programs in building developmental assets among young adolescents: a national survey of services and staff training needs. Child Welfare 1997;76:611-35.

9 Orubuloye IO, Caldwell JC, Caldwell P. Perceived male sexual needs and male sexual behavior in southwest Nigeria. Soc Sci Med 1997;44:1195207

10 Adelekan M, Abiodun O, Imouokhome-Obayan A, Oni G, Ogunremi O. Psychosocial correlates of alcohol, tobacco and cannabis use: findings from a Nigerian university. Drug Alcohol Depend 1993;33:247-56. 


\section{What is already known on this topic}

In 2000 Nigeria developed a national health policy aimed at preventing behaviour among adolescents leading to sexually transmitted infections (including HIV), pregnancy, and dropout from school

Effective interventions in Nigeria have been hampered by inadequate information on contextual factors associated with sexual behaviour of adolescents

In Western countries adolescents' sense of connectedness to their parents and to school is inversely associated with risky sexual behaviour, but these effects may differ in countries where polygamy is prevalent and where school attendance is low

\section{What this paper adds}

A polygamous family structure is associated with early sexual activity among adolescents, an effect partly explained by a higher likelihood of marriage and history of forced sexual intercourse

A greater sense of connectedness to parents and school decreases the likelihood of sexual activity, regardless of family structure

11 Cherian VI. Academic achievement of children from monogamous and polygamous families. J Soc Psychol 1990;130:117-9.
12 Cherian VI. Corporal punishment and academic achievement of Xhosa children from polygynous and monogamous families. J Soc Psychol 1994;134:387-9.

13 Johnson N, Elmi A. Polygamy and fertility in Somalia. J Biosoc Sci 1989;21:127-34.

14 Peterson S. Marriage structure and contraception in Niger. J Biosoc Sci 1999;31:93-104

15 Wold B, Aaro LE, Smith C. Health behaviour in school-aged children: a WHO cross-national survey. Research protocol for the 1993/94 study. Bergen: Research Centre for Health Promotion, University of Bergen, 1994

16 Centers for Disease Control and Prevention. Youth risk behavior surveillance-United States, 1999. MMWR CDC Surveill Summ 2000;49(SS5):1-32.

17 Resnick MD, Bearman PS, Blum RW, Bauman KE, Harris KM, Jones J, et al. Protecting adolescents from harm: findings from the national longitudinal study on adolescent health. JAMA 1997;278:823-32.

18 Baron RM, Kenny DA. The moderator-mediator variable distinction in social psychological research: conceptual, strategic, and statistical considerations. J Pers Soc Psychol 1986;51:1173-82.

19 Owuamanam D. Adolescents' perceptions of a polygamous family and its relationship to self-concept. Int J Psychol 1992;19:593-8.

20 Oyefeso A, Adegoke A. Psychological adjustment of Yoruba adolesents as influenced by family type: a research note. J Child Psychol Psychiatry 1992;33:785-8.

21 Vance PC. Love and sex: can we talk about that in school? Child Educ 1985;61:272-6.

22 Fisher F. Family communication and the sexual behavior and attitudes of college students. J Youth Adolesc 1987;16:481-95.

23 Handelsman CD, Cabral RJ, Weisfeld GE. Sources of information and adolescent sexual knowledge and behavior. J Adolesc Res 1987;2:455-63.

24 Brooks-Gunn J, Furstenberg FFJ. Adolescent sexual behavior. Am Psychol 1989;44:249-57.

25 Pick S, Palos PA. Impact of the family on the sex lives of adolescents. Adolescence 1995;30:667-75.

26 Barone C, Ickovics JR, Ayers TS, Katz SM, Voyce CK, Weissberg RP. Highrisk sexual behavior among young urban students. Fam Plann Perspect 1996;28:69-74.

27 Allan Guttmacher Institute. Can more progress be made? Teenage sexual and reproductive behavior in developed countries (executive summary). Washington, DC: Allan Guttmacher Institute, 2001.

28 Kirby D. Emerging answers: research findings on programs to reduce teen pregnancy (summary). Washington, DC: National Campaign to Prevent Teen Pregnancy; 2001.

(Accepted 12 September 2002) 